\title{
Diagnostic 'Errors' in a Single Urogenital Pathology Unit
}

\author{
Maria Rosaria Cardillo*
}

Department of Experimental Medicine and Pathology (Section of Pathologic Anatomy, Service of Uropathology), University "La Sapienza", Rome, Italy

\begin{abstract}
To understand better the factors that contribute to diagnostic errors in urogenital pathology units, as part of our ongoing research into urogenital cancers, from a consecutive series of 6304 histologic reports for the years 2003 to 2006 we selected for review those containing more than one evident error. We reviewed 1746 urogenital histopathologic diagnoses, $1459(83.56 \%)$ referred to biopsies and $287(16.43 \%)$ to surgical specimens. Of the 1746 reports reviewed, 1643 diagnoses $(94.10 \%)$ were in agreement and $103(5.89 \%)$ in disagreement with the reviewer's rating. Among these 103 diagnoses, 77 (70.75\%) had justifiable and 27 (26.21\%) unjustifiable discordances. Of these 27 discordances, 23 were unjustifiable discordances containing errors with consequences that affected patient management. The poor diagnostic efficiency found in a single anatomopathological unit raises concern and suggests considerable room for improvement. Efficiency could be substantially improved if pathological services strictly applied the existing international measures for quality control.
\end{abstract}

Keywords: Urogenital pathology, histologic errors, quality control.

\section{INTRODUCTION}

Medical errors are found at all levels of patient care: $47.7 \%$ are surgical and $52.3 \%$ non surgical (Gallagher NEM 2007 [1] (Graber JQPS 2005) [2]. About 5-10\% of medical errors are detected during autopsy. In many patients the immediate cause of death is an underdiagnosed [3]. The estimated discordance between clinical and autopsy diagnoses of malignant neoplasms reaches 44\% (Burton JAMA 1998) [3]. The diagnosis of many diseases is based almost exclusively on histologic or cytologic evaluation (Raab Cancer 2005) [4]. The choice of treatment often depends largely on the histopathologic assessment of tissues. Even if no studies have definitively assessed the effect of diagnostic cancer errors on patient outcome a delayed, omitted, wrong or incomplete histo-cytologic report may lead to incorrect patient management plans and delays in treatment or implementation of incorrect treatment regimens. A delayed histocytologic report can cause a patient physical as well as psychological stress (Raab Cancer 2005) [4] (Raab CLM 2004) [5] (Clary AJCP 2002) [6]. Numerous studies have documented a lack of consensus amongst pathologists for a range of specimen types (Raab APLM 2005) [7]. The same pathologist can also examine the same specimen on various occasions but produce different reports (Raab APLM 2005) [7].

The frequency of anatomic pathology errors ranges from $1-43 \%$ (Raab APLM 2005) [7]. The effect of these errors is unknown mainly owing to the lack of uniform measurement processes and pathologists' fear that their errors could have medico-legal implications, thus causing their suspension, and ultimately destroying their professional reputation and private life (Lesna JCP 1998) [8]. In the diagnosis of cancer

*Address correspondence to this author at the Department of Experimental Medicine (Section of Pathologic Anatomy), University "La Sapienza", Policlinico Umberto I, 324 Viale Regina Elena, 00161 Rome, Italy; Tel: 0039.06.49972417; Fax: 0039.06.4454820;

E-mail: mariarosaria.cardillo@uniroma1.it or maria.rosaria.cardil@alice.it these errors reach about $11.8 \%$ (Raab Cancer 2005) [4] (Raab CLM 2004) [5] (Raab APLM 2005) [7] (Nodit AJCP 2005) [9] (Grzybicki AJCP 2005) [10]. In various countries, health care organizations are developing standard programs and laws designed to reduce error and improve patient safety. Many have also implemented an educational campaign that encourages hospitals to integrate their risk management, patient safety, and quality programs (Nodit AJCP 2005) [9] (Grzybicki AJCP 2005) [10] (NQF 2007) [11] (Becher HA 2001) [12] (Joannidis JGIM 2001)[13] JCAHO JQI 1998 [14] (Kizer MGM 2001) [15] (Meyer HSR 2001) [16] (Meyer AJM 2001) [17] (Leape JtCJQI 2000) [18] Silver JtCJQI 2000) [19] (Stump AJHSP 2000) [20]. The processes by which these standards are monitored differ according to the geographical and political contexts.

To maintain standards of medical care, in Italy, the Health Ministry introduced the UNI EN ISO 9001-2000 System Quality Certificate, an award given to health care structures that meet the required quality criteria (Marucci Pathologica 1999) [21]. According to the concept of clinical governance every operative unit (OU) in a hospital should institute a service of risk management that collects the "incident reporting" and integrates their clinical risk-management, patientsafety and quality programs (continuing accredited professional education, randomly organized quality improvement reviews, standardized assessment, and licensure on entry to practice) (Klass NEJM 2007) [22].

A program of quality control (QC) and assurance is essential to reduce diagnostic errors. In pathologic anatomy, similarly to other fields of medicine, errors probably arise from multiple factors (Reason BMJ 2000) [23] (Reason QHC 2001) [24] (Gallagher NEJM 2007) [25]. Institutes of pathologic anatomy use several methods to detect errors (Raab Cancer 2005) [4]; (Nodit AJCP 2005) [9] (Grzybicki AJCP 2005) [10] (Ramsay Histopathology 1999) [26]. The most commonly used is the secondary review, in which a second pathologist reviews slides previously examined by the first [5]. Even though many institutes admitted recogniz- 
ing the sources of these errors the percentage of errors remained constant in the ensuing years, mainly because only few hospitals currently apply the regulations even though physicians generally endorsed the importance of disclosing harmful errors to patients and institutions (Klass NEJM 2007) [22] (Reason BMJ 2000) [23] (Reason QHC 2001) [24] (Gallagher NEJM 2007) [25] (Ramsay Histopathology 1999) [26] (ADASP AJSP 1991) [27] (AJCC Cancer Staging Manual $6^{\text {th }}$ Ed 2002) [28].

In Italy, only few institutions have implemented QC in pathologic anatomy services (Marucci Pathologica 1999) [21]. Before implementing QC and audit, hospitals need precise information on the incidence of diagnostic errors or discrepancies or both accruing in their pathologic anatomy services.

As part of our ongoing research project investigating the pathogenetic mechanisms underlying urogenital cancers (Gandini CR 2003) [29] (Gentile IJIP 2006) [30] (Cardillo AR 2006) [31] (Patraki IJIP 2007) [32], in this study we sought to understand possible factors contributing to anatomic pathology errors in one of the five pathologic anatomy services belonging to an Italian university hospital, and to investigate the clinical impact of anatomic pathology errors on patient care, therapy and outcome. To do so, from a consecutive series of 6304 urogenital histologic reports for the department for the years 2003 to 2006 we selected for review those containing potential errors and diagnostic discrepancies and calculated the percentage of diagnostic errors. To have a more complete idea of the specific problems inherent to a service of urogenital pathology, we focussed our review on the urogenital system.

\section{MATERIAL AND METHODS}

From a consecutive series of 6304 final diagnostic histopathologic reports related to the diagnosis of urogenital tumors recorded from February 2003 to June 2006 in a Service of Pathologic Anatomy at the "Sapienza" University, Rome (Italy) and drawn up by two primary pathologists together with the head of the service, we selected for study 1746 reports for which an initial reading disclosed more than one of the following errors: incorrect identification of patients or incomplete clinical history, secretarial typing errors, discrepancies between macroscopic and microscopic diagnoses, and histotype or tumor node and metastases (TNM) staging omitted. We then reclassified, graded and staged all the tumors according to the classification of the American Joint Committee on Cancer 2002 and the WHO 2002 and 2004 (Humphrey ASCP 2003) [33] (Eble IARC 2004) [34] (Murphy AFIP 2004) [35] (Fuhrmann AJSP 1982) [36] (Bostwick USP 1997)[37]. Of the 1746 urogenital histologic reports selected for review $1459(83.56 \%)$ referred to urogenital biopsies and 287 (16.32\%) to urogenital surgical specimens. The 1746 urogenital pathology reports reviewed referred to the following anatomic sites: 1152 to prostate, 550 to bladder, 52 to kidney, 62 to testis, and 24 to penis and 1 to the adrenal gland. To identify the type of diagnostic error, and the diagnostic step involved we evaluated the following variables: the mean time of final report from tissue reception to report transcription (in days); incorrect identification of patients or incomplete clinical history; adequacy of sample size; secretarial typing errors; technical problems (sample fixation, cutting and staining) and the final diagnostic report (signed by the primary pathologist or by both primary and consultant pathologists) given to the patient's physician. We then calculated the percentage of diagnostic errors. In accordance with previous Italian studies (Marucci Pathologica 1999) [21] we grouped differences of opinion between observers into two categories: justifiable discordances (for example inappropriate assigning of a score, grade or stage to a disease), and unjustifiable discordances (a true diagnostic error, for example, a benign rather than a malignant lesion). To investigate the clinical impact of anatomic pathology errors on patient management, diagnostic errors were divided into two subclasses: with and without consequences for the patient's outcome (different therapeutic approaches, for example hormone, surgical or chemiotherapy or radiotherapy) (Marucci Pathologica 1999) [21]. The diagnostic categories collected were evaluated for each year and for the various tissues and organs.

\section{RESULTS}

The main problems, detected in the 1746 final histologic reports reviewed were incomplete or inaccurate clinical information, inadequate tissue sampling, lengthy time needed for processing specimens, reading and interpreting slides, and producing and transcribing reports (Table 1). In particular, of these 1746 histologic reports, $103(5.89 \%)$ contained diagnostic discordances: 77 (74.75\%) were justifiable and 27 (26.21\%) unjustifiable. Of the reports containing unjustifiable discordances, 23 contained errors with consequences that had affected patient management and 4 showed errors without consequences for the patients (Table 2). These 23 questionable reports that might have had consequences for the patients were reviewed by an external pathologist with acknowledged expertise in urogenital pathology. In all 23 cases the reviewer's and external pathologist's diagnoses were in agreement. Analyzing the diagnostic categories related to organs and year, we found that the percentage of discordance in the reports from the prostate and the bladder samples was higher for the year 2005 than for the years 2004 or 2003: $8.23 \%$ vs $2.78 \%$ vs $2.48 \%$ for prostate and $34.61 \%$ vs $7.32 \%$ vs $6.97 \%$ for bladder (Table 3 ).

Diagnostic discordance differed in surgical and biopsy specimens and differed according to anatomic sites. In the 287 surgical specimens, differences of opinion were greater in the prostate and kidney than in the bladder and testis (9.86\% and $17.64 \%$ vs $5.26 \%$ ). Unjustifiable discordances for the surgical specimens reached $28.57 \%$. Among these, 4 reports referring to nephrectomy and renal tumorectomy all led to unjustifiable discordance with consequences for patients (Table 4). In the 1459 biopsy specimens, the percentage of differences in opinion was higher in the bladder than in the prostate $(10.34 \%$ vs $2.60 \%)$ with unjustifiable discordances in $28.00 \%$ of histological reports. Discordance with consequences for the patient was higher in prostatic and bladder biopsy or transurethral prostatic resection (TURP)/ transurethral bladder resection (TURB) than in ureter, testis and penis biopsies (Table $\mathbf{5}$ ).

Between the 103 diagnostic discordances, considerable disagreement between the two observers was found on assessing the histotype of the histologic diagnosis (39 reports, $37.86 \%$ ). They disagreed on tumor (TNM) staging (22 re- 
Table I. Problems Found in the $\mathbf{1 7 4 6}$ Histologic Reports Selected For Study

\begin{tabular}{|c|c|c|c|}
\hline Total No. of Reports & & 6304 & $(\%)$ \\
\hline Reviewed cases & Mean \pm SD & 1.746 & (27.69) \\
\hline Time required for cutting the surgical specimens (from 3 to 7 days) & $5.90+1.28$ & & \\
\hline Time for preparing the slides (from 3 to 8 days) & $6.11 \pm 2.02$ & & \\
\hline Time for the diagnostic report of biopsies (from 5 to 15 days) & $9.41 \pm 3.11$ & & \\
\hline Time for the diagnostic report of surgical specimens (from 10 to 20 days) & $17.78 \pm 2.25$ & & \\
\hline Typing errors & & 15 & $(0.86)$ \\
\hline Lack of unified histological reports ${ }^{1}$ & & 100 & $(5.72)$ \\
\hline Lack of information on previous histological report ${ }^{2}$ & & 50 & $(2.86)$ \\
\hline Missing review of previous histological report & & 8 & $(0.45)$ \\
\hline Special staining omitted & & 20 & $(1.14)$ \\
\hline Special staining not mentioned in the report & & 15 & $(0.85)$ \\
\hline Diagnosis not corrected & & 12 & $(0.68)$ \\
\hline Inadequate gross description of surgical specimens ${ }^{3}$ & & 12 & $(0.81)$ \\
\hline Modified gross description of surgical specimens ${ }^{4}$ & & 5 & $(0.26)$ \\
\hline Incomplete diagnosis & & 95 & $(5.44)$ \\
\hline Reports not signed or with signature altered & & 45 & $(2.57)$ \\
\hline Diagnostic errors & & 103 & $(5.89)$ \\
\hline \multicolumn{4}{|l|}{ 1. When the report is sent to two departments. } \\
\hline \multicolumn{4}{|c|}{ 2. Worksheet fails to mention that the patient underwent two separate histologic examinations. } \\
\hline \multicolumn{4}{|l|}{ 3. Macroscopic description inadequate. } \\
\hline 4. Original macroscopic description altered. & & & \\
\hline
\end{tabular}

ports, $21.35 \%)$, depth of invasion and histologic grade (10 reports, $9.70 \%$ ), and the macroscopic and microscopic description of the lesion (2 reports, 1.94\%) (Table 6).

Table 2. Reviewed Histopathologic 1746 Reports According to the Category of Diagnostic Discrepancies

\begin{tabular}{|l|c|}
\hline \multicolumn{1}{|c|}{ Category } & No. of Histologic Reports (\%) \\
\hline \hline Concordant & $1643(94.10)$ \\
\hline Discordant & $103(5.89)$ \\
\hline - justifiable & $77 / 103(74.75)$ \\
\hline - unjustifiable: & $27 / 103(26.21)$ \\
\hline • with consequences & $23 / 27(85.18)$ \\
\hline • without consequences & $4 / 27(14.81)$ \\
\hline
\end{tabular}

* Justifiable discordance (for example disagreement in grading or stage evaluation).

** Unjustifiable (a true diagnostic error).

The category of discordance is divided into two subclasses: with consequences and without consequences for the outcome and therapy of the patient.

\section{DISCUSSION}

In this retrospective review of 1746 selected urogenital histologic reports from a single academic service of pathologic anatomy, we found a $5.89 \%$ frequency of diagnostic errors. This finding agrees with previous reports describing a frequency of anatomic pathologic errors ranging from $1-43 \%$ for all specimens and in cancer diagnosis from 1.79-9.42\% and from $4.87-11.8 \%$, depending on the institution (Raab Cancer 2005) [4].

Previous retrospective studies of error rates have produced widely varying results. Whereas one large study found no "serious" errors (Cree PRP 1993) [38] others have suggested that $0.26 \%$ (Safrin AJSP 1993) [39] or even up to $1.2 \%$ (Lind AJCP 1995) [40] of histopathological reports are likely to contain a clinically significant error. Another clinical-pathological series showed an altered diagnosis in $9 \%$ of cases, resulting in major management changes in $3.8 \%$ (McBroom AJSP 1993) [41]. These discrepancies could arise partly from the variability in pathologists' skills, experience and results, and also from the high inter-institutional variability in assigning the cause of error, diagnostic differences related to the various organ systems investigated, and the lack of uniform measurement processes (Silver JtCJQI 2000) [19]. Hence we agree with others that to define the percentage of diagnostic errors in a single pathologic anatomy service reliably we need first to standardize methods for assessing errors (Furness JCP 1997) [42].

To investigate the clinical impact of anatomic pathology errors on patient care, therapy and outcome, in accordance with previous Italian studies (Marucci Pathologica 1999) 
Table 3. Diagnostic Categories Related to Organs and Year

\begin{tabular}{|c|c|c|c|c|c|c|c|c|c|c|c|c|}
\hline & Year & Concordant & Discordant & Year & Concordant & Discordant & Year & Concordant & Discordant & Year & Concordant & Discordant \\
\hline \begin{tabular}{c|} 
Reports \\
Reviewed
\end{tabular} & 2003 & $\begin{array}{c}\text { No. of } \\
\text { Cases (\%) }\end{array}$ & $\begin{array}{c}\text { No. of } \\
\text { Cases (\%) }\end{array}$ & 2004 & $\begin{array}{c}\text { No. of } \\
\text { Cases (\%) }\end{array}$ & $\begin{array}{c}\text { No. of } \\
\text { Cases (\%) }\end{array}$ & 2005 & $\begin{array}{c}\text { No. of } \\
\text { Cases (\%) }\end{array}$ & $\begin{array}{c}\text { No. of } \\
\text { Cases }(\%)\end{array}$ & 2006 & \begin{tabular}{c|} 
No. of \\
Cases $(\%)$
\end{tabular} & $\begin{array}{c}\text { No. of } \\
\text { Cases (\%) }\end{array}$ \\
\hline Prostate & 719 & $699(97.21)$ & $20(2.78)$ & 322 & $314(97.51)$ & $8(2.48)$ & 85 & 78 (91.76) & $7(8.23)$ & 26 & 25 & 1 \\
\hline Bladder & 396 & $267(92.67)$ & $29(7.32)$ & 86 & $80(93.02)$ & $6(6.97)$ & 52 & $34(65.38)$ & $18(34.61)$ & 16 & 15 & 1 \\
\hline Kidney & 41 & $34(82.92)$ & 7 & 11 & 9 & 2 & 0 & 0 & 0 & 0 & 0 & 0 \\
\hline Testis & 47 & 45 (95.74) & 2 & 11 & 10 & 1 & 2 & 2 & 0 & 2 & 2 & 0 \\
\hline Penis & 21 & 21 & 0 & 3 & 3 & 0 & 0 & 0 & 0 & 0 & 0 & 0 \\
\hline Total & 1.224 & $1.066(87.09)$ & $58(4.73)$ & 433 & $416(96.03)$ & $17(4.08)$ & 139 & $114(82.01)$ & $25(17.98)$ & 44 & $42(95.45)$ & $2(4.76)$ \\
\hline
\end{tabular}

Table 4. Diagnostic Categories Related to Tissue Type (287 Surgical Specimens)

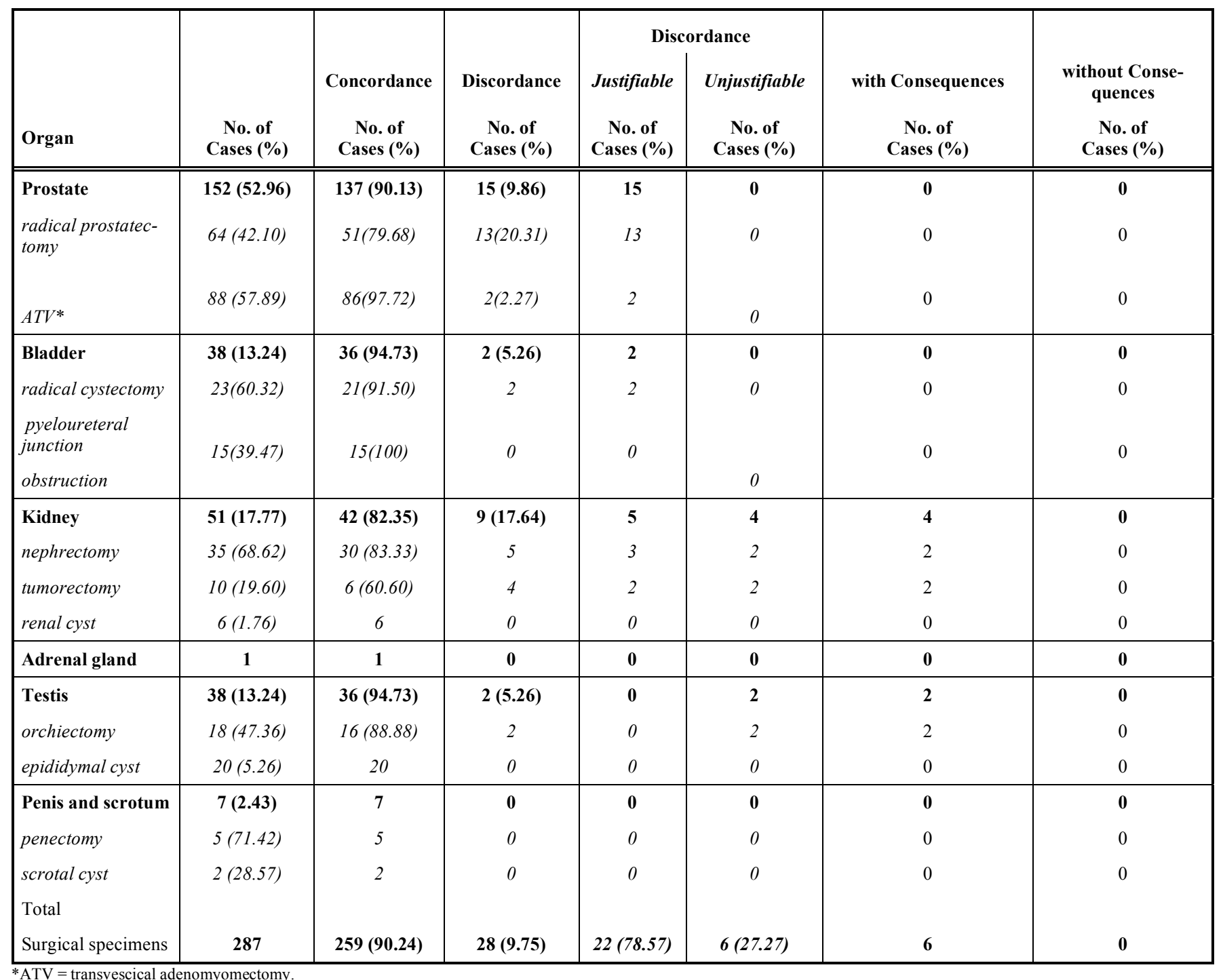

[21], we classified justifiable and unjustifiable errors and divided the discordance category into two subclasses: without consequences and with consequences for the patient. Because mistakes in grading and staging can have consequences for the patients this classification might in future be usefully reappraised to include these inaccuracies as unjustifiable rather than justifiable errors. Conversely, other studies designed to assess the clinical severity of errors, graded the categories of severity errors as minimal (grade1), moderate (grade 2), and severe (grade 3) harm (Raab Cancer 2005) [4]. 
Table 5. Diagnostic Categories Related to Tissue Type (1459 Biopsies)

\begin{tabular}{|c|c|c|c|c|c|c|c|}
\hline Organ & $\begin{array}{c}\text { No. of } \\
\text { Cases (\%) }\end{array}$ & $\begin{array}{l}\text { Concordance } \\
\begin{array}{c}\text { No. of } \\
\text { Cases }(\%)\end{array}\end{array}$ & $\begin{array}{l}\text { Discordance } \\
\\
\text { No. of } \\
\text { Cases (\%) }\end{array}$ & $\begin{array}{c}\text { Discordance } \\
\text { Justifiable } \\
\text { No. of } \\
\text { Cases (\%) }\end{array}$ & $\begin{array}{c}\text { Discordance } \\
\text { Unjustifiable } \\
\text { No. of } \\
\text { Cases (\%) }\end{array}$ & $\begin{array}{c}\text { with Consequences } \\
\text { No. of } \\
\text { Cases (\%) }\end{array}$ & $\begin{array}{l}\text { without Consequences } \\
\text { No. of } \\
\text { Cases (\%) }\end{array}$ \\
\hline Prostate & $902(55.92)$ & $879(97.45)$ & $23(2.60)$ & $10(43.47)$ & $13(56.52)$ & $10(76.92)$ & $3(23.07)$ \\
\hline Biopsy & $703(77.93)$ & $682(97.01)$ & $21(2.57)$ & $10(47.61)$ & $11(52.38)$ & $8(72.72)$ & $3(27.27)$ \\
\hline$T U R P^{*}$ & $199(22.06)$ & 197 (98.99) & $2(1.05)$ & 0 & 2 & 2 & 0 \\
\hline Bladder & $493(30.56)$ & $442(89.65)$ & $51(10.34)$ & $43(84.31)$ & $8(15.38)$ & $7(87.50)$ & $1(12.50)$ \\
\hline Biopsy & $357(72.41)$ & 327 (91.59) & $30(8.40)$ & 25 (92.59) & $2(8)$ & 2 & 0 \\
\hline$T U R B^{*}$ & $136(27.58)$ & $115(84.55)$ & $21(15.44)$ & $19(76.00)$ & $6(24)$ & 5 & 1 \\
\hline $\begin{array}{l}\text { Ureter and } \\
\text { urethra }\end{array}$ & $25(1.54)$ & 25 & 0 & 0 & 0 & 0 & 0 \\
\hline Testis & $20(1.23)$ & 19 & 1 & 1 & 0 & 0 & 0 \\
\hline Penis & $19(1.17)$ & 19 & 0 & 0 & 0 & 0 & 0 \\
\hline Total biopsies & 1459 & $1384(94.85)$ & $75(5.14)$ & $55(72.00)$ & $21(28.00)$ & $17(80.95)$ & $4(19.04)$ \\
\hline
\end{tabular}

*TURP $=$ transurethral resection of prostate.

An unexpected finding in our study was the high discordance in surgical specimens (28 of 287 specimens $9.75 \%$ ). Of these, $6(27.27 \%)$ were unjustifiable discrepancies and all 6 (4 referring to nephrectomy and renal tumorectomy and 2 to orchiectomy) had consequences for the patients (Table 4). The altogether unacceptable frequency of unjustifiable discordance we found in the surgical specimens would probably be avoided if pathology units strictly followed the diagnostic criteria stated in the current guidelines (Eble IARC 2004) [34] (Murphy AFIP 2004) [35] (Fuhrmann AJSP 1982) [36] (Bostwick USP 1997) [37].

Table 6. Type of Histologic Disagreement in 103 of 1746 Histologic Reports

\begin{tabular}{|l|c|}
\hline & No. of Cases (\%) \\
\hline \hline Total Number of Diagnostic Discrepancies & $\mathbf{1 0 3}(\mathbf{5 . 8 9 )}$ \\
histotype & $39(37.86)$ \\
tumor grading & $10(9.70)$ \\
tumor staging (TNM) & $22(21.35)$ \\
histotype omitted & $10(9.70)$ \\
grade invasion or tumor differentiation omitted & $10(9.70)$ \\
tumor staging (TNM) omitted & $10(9.70)$ \\
discrepancies between macroscopic and histologic & $2(1.94)$ \\
diagnoses & \\
\hline
\end{tabular}

In urogenital biopsies the high incidence of discordance with consequences-for patients with prostatic and bladder cancer $(76.92 \%$ and $87.50 \%)$ are in line with previous reports in specific areas of surgical pathology such as skin, lymphoreticular and gastrointestinal systems, prostate and bladder biopsies, describing a "failure to diagnose" category (oversight errors) in $87 \%$ of the medicolegal claims (Raab APLM 2005) [7] (Lesna JCP 1998) [8] (Ramsay Histopathology 1999) [26] (Furness JCP 1997) [42]. The highest incidence of diagnostic discordances in our study was related to tumor histotype (37.86\%) and TNM staging (21.35\%).

When we reviewed prostate specimens obtained through fine needle biopsy, we noted especial difficulties in interpreting minute foci of atypical acini (atypical hyperplasia (AHP) vs atypical small acinar proliferation (ASAP) vs welldifferentiated prostate adenocarcinoma (PCA) (Montironi EU 2006) [43], and of atypia in neoplastic prostate glands after hormonal or radiotherapy (Sung HP 2007) [44]. The main causes of discordance in the prostate specimens obtained through TURP were problems in assessing the histological grade of intraepithelial prostatic neoplasia (PIN) (low-grade $v s$ high-grade PIN; high-grade PIN vs microinvasive PCA), and in assessing the Gleason score histologic grading (Montironi NCPU 2007) [45] (Montironi JCP 2007) [46]. The diagnosis of low-grade PIN should not be reported at all (Bostwick USP 1997) [37], whereas a diagnosis of high-grade PIN suggests that the patient should undergo regular follow-up to detect the possible development of prostate cancer (Bostwick USP 1997) [37]. In the specimens obtained from radical prostatectomies, we found considerable disagreement in assessing the pathologic stage (TNM). For example, the discordance in tumor staging often depended on diagnostic issues. If the tumor involved one or both prostate lobes, extended beyond the prostate or invaded the seminal vesicles these histological findings were sometimes missed (Table 6). In specimens obtained from prostatic biopsies, the most frequent cause of errors in our series was the scarce use or wrong interpretation or both (sometimes owing to technical problems) of prostatic-specific immune markers (34betaE12, p63, racemase).

In the bladder biopsies our review detected a variable number of errors. Most errors arose from interpreting and defining the histotype (for example, neoplasia with low malignant potential $v s$ low-grade malignant carcinoma; lowgrade $v s$ high-grade urothelial carcinoma; urothelial hyperplasia $v s$ dysplasia $v s$ in situ carcinoma); and from grading or 
evaluating the depth of tumor invasion (Murphy AFIP 2004) [35]. In radical cystectomies, the disagreement concerned the pathologic stage (TNM). Many bladder tumors were over- or under staged. Diagnostic errors arose mainly from a lack of clinical information, and a failure to include previous pathology reports and radiographic studies. The diagnostic discordances in interpreting and defining the histotype and grade of urothelial carcinoma often reflected a reluctance to use the newer classification systems; whereas the discordance in tumor stage arose from a poor knowledge of the staging guidelines, inability to identify muscularis propria invasion and the scarce use of the immune markers cytokeratin 7 and 20 [46].

In the reports regarding tissue from renal nephrectomies or tumorectomies, the potential pitfalls our review underlined were the diagnosis of benign or malignant tumour (adenoma $v s$ clear-cell carcinoma $v s$ oncocytoma) or the differential diagnosis of several histological subtypes of renal cell carcinoma (papillary renal cell type I vs type II; clear cell vs chromophil; chromophil vs chromophobe renal cell, spindle cell vs collecting duct carcinoma). Previous studies showed that adding fluorescence in situ hybridization (FISH) analysis to histopathology might improve the accuracy of kidney tumor diagnoses (Iqbal ASM 1999) [48] (Paner APLM 2007) [49] (Delaney Histopathology 2005) [50], by detecting chromosome abnormalities which are specific for various renal cell carcinoma subtypes and by providing important prognostic information that can guide management decisions. These findings again underline the need for continual professional training to encourage the use of advanced immunohistochemical and molecular techniques thus improving diagnostic accuracy.

In the testicular biopsies done for sterility, our review showed that many final reports were incomplete or inaccurate. In tumor neoplasias, the major factors that limited the morphological diagnosis and assessment of the pathologic stage were the lack of clinical information at the correct time (patient's history, previous plasma tumoral markers and radiographic studies) and the failure to include in the final report essential histologic information such as vascular invasion, and margin infiltration (Delaney Histopathology 2005) [50].

Because many records lacked information on follow-up we could have underestimated the percentage of reports containing unjustified errors with consequences for the patient. For the same reason, our study leaves unanswered the question of how these anatomic pathology errors, especially those for cancer, affected our patients' care, clinical outcome, survival and quality of life. Previous studies have underlined that a false-positive prostate biopsy, for example, might cause a wrongful prostate surgical resection or prostatectomy (Lessells 172 ${ }^{\text {nd }}$ Meeting PSGBI 1996) [51] (Leong Pathology 2006) [52] (Piotrowski JCJQPS 2005) [53]. Conversely, a false negative report, for example a diagnosis of renal adenoma instead of renal cell carcinoma or benign prostatic hyperplasia instead of prostatic carcinoma, could delay therapy (Raab Cancer 2005) [4]. In bladder tumors, for example, the therapy in superficial urothelial (TA/T1) carcinoma differs from deep (T2/T3) carcinomas; and in low-grade (G1) tumors differs from high-grade (G2/G3) malignancy (Kirkali Urology 2005) [54].
In seeking to understand better the factors that contribute to errors and error-reduction strategies another question is the stage of the diagnostic procedure most prone to errors (Nakhleh APLM 2006) [55]. Our study showed that major problems arose in all phases of the diagnostic procedure. In the preanalytic phase when specimens are obtained from the patient and transported to the pathology section, our review disclosed incomplete or inaccurate clinical information, and inadequate tissue sampling. In the analytic phase, starting with the arrival of specimens at the pathology station and terminating with the release of the pathology report, undue time was needed for processing specimens, and reading and interpreting slides. In the postanalytic phase, involving the receipt and follow-up of the pathology report by the ordering clinician, errors arose and the final reports took unduly long to produce and transcribe. Recognizing the major diagnostic pitfalls in urogenital pathology may help to improve safety by reducing the high rate of errors in a specific type of specimens, by applying protocols to control the sequence of events throughout the diagnostic procedure, and especially by developing error-reduction strategies by audit in histopathology (Raab CLM 2004) [5], (Marucci Pathologica 1999) [21], (ADASP AJSP 1991) [27] (AJCC Cancer Staging Manual $6^{\text {th }}$ Ed 2002) [28] (Cree PRP 1993) [38] (Nakhleh APLM 2006) [55] (College of American Pathologists 2000) [56]. This systematic procedure often compels academic institutions to change their frame of mind thus becoming open to changes that will effectively improve the quality of anatomic pathology services and adhering to the international monitoring criteria reported by the Armed Forces Institute of Pathology (College of American Pathologists 2000) [56]. An internal committee monitors the level of compliance to guarantee the efficiency and quality of the services (internal quality assessment (IQA); to compare frozen section diagnoses with the final paraffin section diagnosis (intraoperative consultation); to select rare, difficult or unusual cases to send to a consulting pathologist specialist in the areas of interest, particularly in cases in which the primary and concurring pathologists could not reach consensus; to institute monthly, reviews and discuss retrospectively the internal and external pathology consultations; and to promote regional and extraregional slide seminaries (external quality assessment (EQA) (Marucci Pathologica 1999) [21] (ADASP AJSP 1991) [27] (AJCC Cancer Staging Manual $6^{\text {th }} \mathrm{Ed}$ 2002) [28] (Nakhleh APLM 2006) [55] (Conroy ACP News 1996) [57]. Unfortunately in our institution as often happens, the final review of the specimen by a specialist was omitted.

Our findings again underline other major factors contributing to diagnostic errors in urogenital pathology. For example, errors seem to increase when colleagues are on annual leave or retire (College of American Pathologists 2000) [56]. In our service, in 2003, after a consultant retired, another consultant together with three primary pathologists moved to the urogenital pathology service from the immunopathology service. This change, involving staff who were new to the customary work patterns in the unit, presumably altered the safe and effective communication process, a prerequisite for error-free diagnosis and essential to avoid system failure the root cause of error (College of American Pathologists 2000) [56]. (Conroy ACP News 1996) [57]. To interpret the number of errors by organ system also requires a knowledge of the work patterns in the departments involved. Even in the 
presence of suboptimal communication, a terminal review of the pathology slides by a consultant pathologist with expertise in the particular field can prevent the error from reaching the patient (Nakhleh APLM 2006) [55]. Because most pathologists working in our service are general pathologists, without specific qualifications in urogenital pathology, the routine use of international guidelines (Humprey ASCP 2003) [33] (Eble IARC 2004) [34] (Murphy AFIP 2004) [35] (Fuhrmann AJSP 1982) [36] (Bostwick USP 1997) [37] is crucial to reduce oversight errors in pathological scoring or grading (Furness JCP 1997) [42]. This conclusion again underlines the need for quality assurance monitoring especially when personnel move to a subspecialty program.

A limitation of the study is a possible inherent selection bias in the cases, because the reports were initially chosen based on identifiable errors seen while reading the initial report thus possibly overestimating or underestimating the discordant errors based on general report quality.

\section{CONCLUSION}

Although our study has limitations because we reviewed histopathology reports from a single specialist anatomic pathology unit (urogenital pathology service) and the findings may not represent the wider picture in all institutions, the information we provide on diagnostic errors should be helpful in planning a modern, efficient, reliable (error-free?) histopathology service.

\section{ACKNOWLEDGEMENTS}

This study was supported by grants from the Ministero Università della Ricerca Scientifica e Tecnologica (M.U.R. S.T) of the Facoltà and Ateneo 2005-2006. The author wishes to thank Professors R. Montironi and I.A. Sesterhenn for kindly giving their opinion on the questionable pathology reports.

\section{REFERENCES}

[1] Gallagher TH, Studdert D, Levinson W. Disclosing harmful medical errors to patients. N Engl Med 2007; 356 (26): 2713-19.

[2] Graber M. Diagnostic Errors in Medicine: a case of neglect. J Qual Patient Saf 2005; 31(2): 106-13.

[3] Burton EC, Troxclair DA, Newman WP. Autopsy diagnoses of malignant neoplasms: how often are clinical diagnoses incorrect? J Am Med Assoc 1998; 280: 1273-74.

[4] Raab SS, Grzybicki DM, Janosky JE, et al. Clinical impact and frequency of anatomic pathology errors in cancer diagnoses. Cancer 2005; 104: 2205-13.

[5] Raab SS. Improving patient safety by examining pathology errors. Clin Lab Med 2004; 24: 849-63.

[6] Clary JM, Silverman JF, Liu Y, et al. Cytohistologic discrepancies: a means to improve pathology practice and patient outcomes. Am J Clin Pathol 2002; 117: 567-73.

[7] Raab SS, Grzybicki DM, Zarbo RJ, Meier FA, Geyer SJ, Jensen C. Patient safety in anatomic pathology: measuring discrepancy frequencies and causes. Arch Pathol Lab Med 2005; 29 (10): 1246-51.

[8] Lesna M. Assessing diagnostic errors: when is suspension of pathologist justified? J Clin Pathol 1998; 51: 649-51.

[9] Nodit L, Balassanian R, Sudilovsky D, Raab SS. Root cause analysis for errors in bronchial washing and brushing specimens. Am J Clin Pathol 2005; 124(6): 883-92.

[10] Grzybicki DM, Turcsanyi B, Becich MJ, Gupta D, Gilbertson JR, Raab SS. Data base construction for improving patient safety by examining pathology errors. Am J Clin Pathol 2005; 124(4): 500509.

[11] Safer practices for better health care. Washington, DC. National Quality Forum, 2007. (Accesssed June 1, 2007, at http://www. qualityforum.org/projects/completed/safe_practices/)
[12] Becher EC, Chassin MR. Improving the quality of health care: who will lead? Health Aff (Millwood) 2001; 20: 164-79.

[13] Ioannidis JPA, Lau J. Evidence on interventions to reduce medical errors: An overview and recommendations for future research. J Gen Intern Med 2001; 16: 325-34

[14] Joint Commission on Accreditation of Healthcare Organizations. Sentinel events: approaches to error reduction and prevention. J Qual Improv 1998; 24: 175-86.

[15] Kizer KW. Patient safety: a call to action: a consensus statement from the National Quality Forum. Med Gen Med 2001; 3: 10.

[16] Meyer G, Foster N, Christrup S, Eisenberg J. Setting a research agenda for medical errors and patient safety. Health Serv Res 2001; 36 (1 pt 1): $\mathrm{x}-\mathrm{xx}$.

[17] Meyer G, Lewin DI, Eisenberg JM. To err is preventable: medical errors and academic medicine. Am J Med 2001; 110: 597-603.

[18] Leape LL, Kabcenell AI, Gandhi TK, Carver P, Nolan TW, Berwick DM. Reducing adverse drug events: lessons from a breakthrough series collaborative. Jt Comm J Qual Improv 2000; 26: 321-31.

[19] Silver MP, Antonow JA. Reducing medication errors in hospitals: a peer review organization collaboration. Jt Comm J Qual Improv 2000; 26: 332-40.

[20] Stump LS. Re-engineering the medication error-reporting process: removing the blame and improving the system. Am J Health Syst Pharm 2000; 57(suppl 4): S10-S17.

[21] Marucci G, Collina G, Damiani S, et al. Controllo di qualità della sezione d'Anatomia, Istologia e Citologia Patologica «M. Malpigli», Dipartimento d'Oncologia, Università di Bologna, Ospedale Bellaria. Pathologica 1999; 91: 268-75.

[22] Klass D. Assessing doctors at work- Progress and challenges. N Engl J Med 2007; 356 (4): 414-15.

[23] Reason J. Human error: models and management. BMJ 2000; 320(7237): 768-70.

[24] Reason JT, Carthey J, de Leval MR. Diagnosing "vulnerable system syndrome": an essential prerequisite to effective risk management. Qual Health Care 2001; Supp12: ii21-25.

[25] Gallagher TH, Studdert D, Levinson W. Disclosing harmful medical errors to patients. N Engl J Med 2007; 356(26): 2713-19.

[26] Ramsay AD. Errors in histopathology reporting: detection and avoidance. Histopathology 1999; 34: 481-90.

[27] Association of Directors of Anatomic and Surgical Pathology. Recommendations on Quality Control and Quality Assurance in Anatomic Pathology. Am J Surg Pathol 1991; 15: 1007-9.

[28] American Joint Committee on Cancer. Cancer Staging Manual 6th Ed. Philadelphia: Lippincott-Raven 2002.

[29] Gandini O, Santulli M, Cardillo MR, Stigliano A, Toscano V. DD3, a very sensitive and specific marker to detect prostate tumors. Cancer Res 2003; 63(15) pp 4747.

[30] Gentile V, Vicini P, Giacomelli L, Cardillo MR, Pierangeli A, Degener AM. Detection of human papillomavirus DNA, p53 and Ki67 expression in penile carcinomas. Int J Immunol Pharmacol 2006; 19(1): 209-15.

[31] Cardillo MR, Ippoliti F. IL-6, IL-10 and HSP-90 expression in tissue microarrays from human prostate cancer assessed by computer-assissed image analysis. Anticancer Res 2006; 26(5A): 340916.

[32] Patraki E, Cardillo MR. Quantitative immunohistochemical analysis of matrilysin 1 (MMP-7) in various renal cell carcinoma subtypes. Int J Immunol Pharmacol 2007; 20(4): 697-705.

[33] Humphrey PA. Prostate Pathology. Ed. American Society for Clinical Pathology (ASCP) 2003; 205.

[34] Eble JN, Sauter G, Epstein JI, Sesterhenn IA. World Health Organization (WHO) Classification of tumours: pathology and genetics of tumours of the urinary system and male genital organs. Ed. Lyons: IARC Press. 2004.

[35] Murphy WM, Grignon DJ, Perlman EJ. Tumors of the kidney, bladder and related urinary structures. AFIP Atlas of Tumor Pathology Series 4. Ed Washington 2004; 160.

[36] Fuhrmann SA, Lasky LC, Limas C. Prognostic significance of morphologic parameters in renal cell carcinoma. Am J Surg Pathol 1982; 6: 655-663.

[37] Bostwick DG, Eble JN. Urologic Surgical Pathology. Ed Mosby, St Louis. 1997; pp. 323-24 and 357-58.

[38] Cree IA, Guthrie W, Anderson JM, et al. Departmental audit in histopathology. Pathol Res Pract 1993; 189: 453-57. 
[39] Safrin RE, Bark CJ. Surgical pathology sign out-routine review of every case by a $2^{\text {nd }}$ pathologist. Am J Surg Pathol1993; 17: 1190-92.

[40] Lind AC, Bewtra C, Healy JC, Sim KL. Prospective peer review in surgical pathology. Am J Clin Pathol 1995; 104: 560-66.

[41] McBroom HM, Ramsay AD. The clinicopathological meeting a means of auditing diagnostic performance. Am J Surg Pathol 1993; 17: 75-80.

[42] Furness PN, Lauder I. A questionnaire-based survey of errors in diagnostic histopathology throughout the United Kingdom. J Clin Pathol 1997; 50: 457-60.

[43] Montironi R, Scattoni V, Mazzucchelli R, Lopez-Beltran A, Bostwick DG, Montorsi F. Atypical foci suspicious but not diagnostic of malignancy in prostate needle biopsies (also referred to as "atypical small acinar proliferation suspicious for but not diagnostic of malignancy"). Eur Urol 2006; 50(4): 666-74.

[44] Sung MT, Jiang Z, Montironi R, MacLennan GT, Mazzucchelli R, Cheng L. Alpha-methylacyl-CoA racemase (P504S)/34 betaE12/p63 triple cocktail stain in prostatic adenocarcinoma after hormonal therapy. Hum Pathol 2007; 38(2): 332-41.

[45] Montironi R, Mazzucchelli R, Lopez-Beltran A, Cheng L, Scarpelli M. Mechanisms of disease: high-grade prostatic intraepithelial neoplasia and other proposed preneoplastic lesions in the prostate. Nat Clin Pract Urol 2007; 4(6): 321-32.

[46] Montironi R, Mazzucchelli R, Scarpelli M, Lopez-Beltran A, Cheng L. Morphological diagnosis of the urothelial neoplasms. J Clin Pathol 2008; 61(1): 3-10.

[47] Barocas DA, Mathew S, DelPizzo JJ, et al. Renal cell carcinoma sub-typing by histopathology and fluorescence in situ hybridization on a needle-biopsy specimen. BJU Int 2007; 99(2): 290-95.
[48] Iqbal MA, Akhtar M, AL Dayel F, Ulmer C, Paterson MC. Use of FISH for diagnosis of renal cell carcinoma subtypes. Ann Saudi Med 1999; 19(6): 495-500.

[49] Paner GP, Lindgren V, Jacobson K, et al. High Incidence of chromosome 1 abnormalities in a series of 27 renal oncocytomas: cytogenetic and fluorescence in situ hybridization studies. Arch Pathol Lab Med 2007; 131(1): 81-85.

[50] Delaney RJ, Sayers CD, Walker MA, Mead GM, Theaker JM. The continued value of central histopathological review of testicular tumours. Histopathology 2005; 47(2): 166-169.

[51] Lessells AM, Burnet RA, Howatson SR, et al. Observer variability in the histological reporting of prostatic needle biopsy specimens (abstract). London, $172^{\text {nd }}$ meeting of the Pathological Society of the Great Britain and Ireland. 1996.

[52] Leong AS, Braye S, Bhagwandeen B. Diagnostic 'errors' in anatomical pathology: relevance to Australian laboratories. Pathology 2006; 38(6): 487-89.

[53] Piotrowski MM, Bassette RL, Chensue S, et al. Learning to improve safety: False-positive pathology report results in wrongful surgery. Jt Comm J Qual Patient Saf 2005; 31(3): 1-7.

[54] Kirkali Z, Chang T, Manoharan M, et al. Bladder cancer: epidemiology, staging and grading, and diagnosis. Urology 2005; 66(Suppl 1): 4-34.

[55] Nakhleh RE. Error reductions in surgical pathology. Arch Pathol Lab Med 2006; 130: 630-32.

[56] College of American pathologists. Standards for laboratory accreditation. 2000. (Accessed 22 November 2007, at http://www.cap.org/ apps/docs/laboratory_accreditation/standards/).

[57] Conroy B. A cause for some concern (letter). ACP News, Wrinter, 1996, 52-4. 